\title{
Stage I Ovarian Cancer AJCC v6 and v7
}

National Cancer Institute

\section{Source}

National Cancer Institute. Stage I Ovarian Cancer AJCC v6 and v7. NCI Thesaurus. Code C7829.

Stage I includes: T1, N0, M0. T1: Tumor limited to ovaries (one or both). N0: No regional lymph node metastasis. M0: No distant metastasis. (AJCC 6th and 7th eds.) 